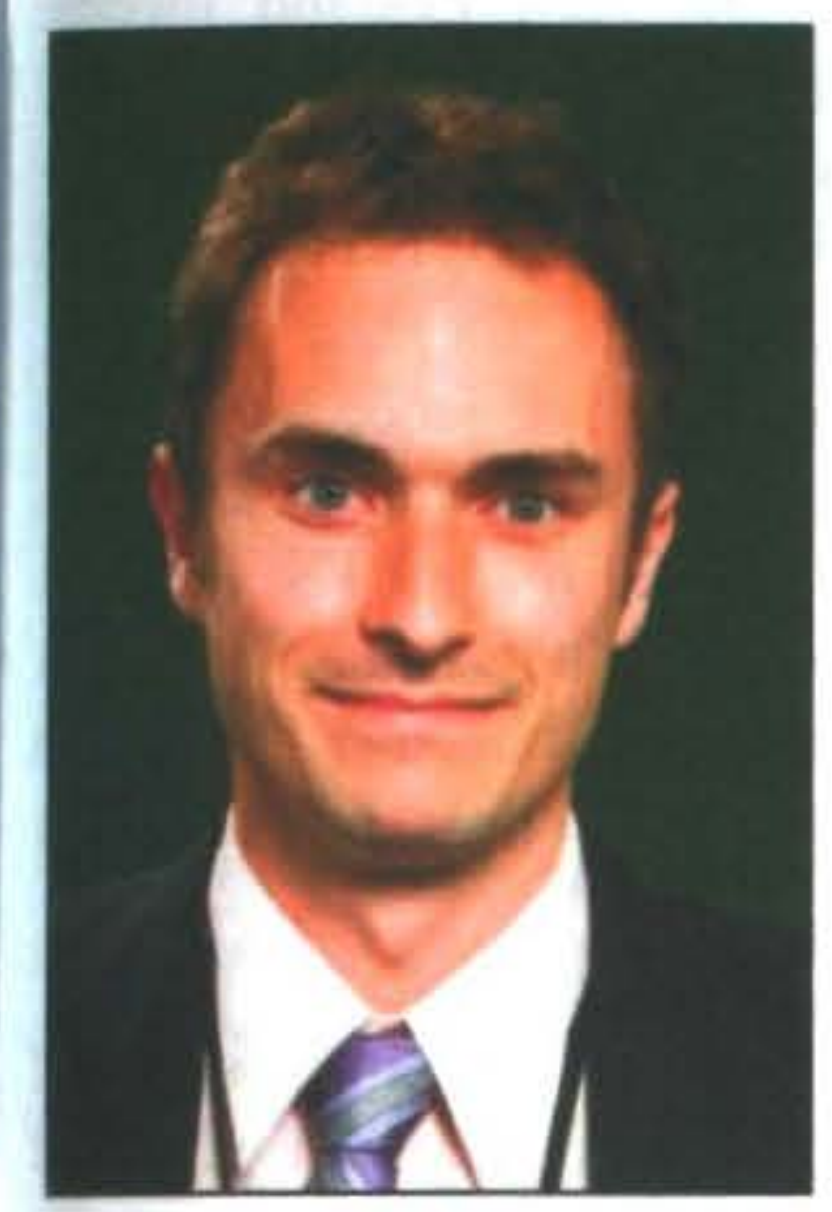

\title{
ADJUSTING FOR CHANGES IN \\ LABOUR COMPOSITION IN \\ STATISTICS NEW ZEALAND'S \\ PRODUCTIVITY SERIES
}

\author{
Thomas McNaughton \\ Macro-Economic Statistics \\ Development Unit \\ Statistics New Zealand
}

\begin{abstract}
In measuring labour productivity, a composition-adjusted series is generally considered to provide the most representative measure of labour input. The rationale for adjusting for changes in labour composition is that workers are not homogenous, and as such, have different skill levels. Not only should this provide a more accurate measure of labour input, but it can also provide insight into the effects that changes in labour composition have on productivity. In practice, this process is undertaken by cross-classifying labour by proxies for skill, such as educational attainment and experience. The relative skill levels of different groups are estimated via regression analysis, through differences in hourly wages. This paper evaluates the various theories behind compositional adjustment, and presents the results of applying such an adjustment to the Statistics NZ labour productivity series, under various conditions. The ultimate contribution of the paper is an experimental composition-adjusted labour productivity series, for which external feedback is welcomed.
\end{abstract}

\section{Introduction}

Labour productivity is measured as the ratio of output (GDP) to labour input. In measuring labour productivity, a labour composition-adjusted series (often referred to as a 'quality-adjusted' series) is generally considered to provide the most representative measure of labour input. The rationale for adjusting an input series for changes in labour composition is that workers are not homogenous, and as such, have different skill levels. Not only should an adjustment for skills provide a more in-depth measure of labour, but it can also provide insight into the effects that changes in labour composition have on productivity. In practice, this process is undertaken by crossclassifying workers by proxies for skill, such as educational attainment and experience. The relative skill levels of different groups are estimated via regression analysis, through hourly wages.

This paper provides background to, and an application of, adjusting for compositional change in the Statistics NZ labour productivity series. Two main approaches to making this adjustment are discussed in the paper, with focus being put on the preferred regression-based approach in which a number of proxies for skill, such as education and work experience, are regressed on workers' wages.

The primary output of this analysis is an experimental composition-adjusted labour volume series for the measured sector of the economy, and a growth accuunting decomposition of gross domestic product (GDP), with this added level of detail covering the period 1998 to 2007 . $^{1}$ This period reflects the availability of the preferred datasets. Over the period, education was clearly the main contributor to the rise in labour quality, although the changing distribution of experience, particularly in the later years, has halted growth in the labour composition series somewhat

The composition-adjusted series has been released as experimental largely because these are series for which Statistics NZ is seeking feedback, prior to consideration of publishing these as official statistics.

\section{Why adjust for labour composition?}

Economic growth can be achieved through increases in either the quantity of inputs, such as labour and capital, or through productivity growth; hence a representative measure of productivity is of high importance when determining the contributions to growth. In practice, productivity is calculated as the ratio of output (GDP) to input(s). Consequently MFP growth is calculated as a residual, defined as growth in GDP that cannot be attributed to capital or labour. This is often referred to as 'disembodied technological change'. This includes factors such as technological change or improvements in knowledge, methods and processes. ${ }^{2}$

To understand the motivation behind compositionadjusting labour volume, we need to have a clear 
definition of what labour input is intended to capture. As the OECD (2001) notes, labour input should reflect the "time, effort and skills of the work force". The common standard for labour input is to use hours as the unit of measurement. This captures the time dimension of labour, but not the skill dimension. When raw hours worked is used in measuring productivity, the coverage of labour input is essentially incomplete, because the skill dimension is not being captured. Instead, changes in the skill level of workers will be captured within the (residual) productivity estimates, implying that these estimates are not a perfect measure of disembodied technological change.

Productivity series feed well into growth accounting analysis, that is, the decomposition of movements in GDP. With the skill aspect measured, growth in GDP can be broken down into growth in multi-factor productivity, growth in raw labour and capital inputs, and growth in labour skills, providing more detailed information into the drivers of economic growth.

The currently published Statistics NZ labour productivity and MFP estimates utilise an hours paid series (known as the labour volume series) that is weighted according to industry wage income shares, under the assumption that the industry of workers is correlated with skills. Although still based on proxies, the approach outlined in this paper uses more specific proxies for measuring labour composition.

\section{How do we measure skill?}

Although theoretically appealing, the application of composition is data intensive, with a dependence on a robust measure of skill to distinguish workers. In similar studies, such as Reilly et al (2005) and Szeto \& McLoughlin (2008), human capital theory has been drawn on to confront this. The OECD (2007) defines human capital as "The knowledge, skills, competencies and attributes embodied in individuals that facilitate the creation of personal, social and economic wellbeing". 3 Human capital theory stipulates that there is a positive relationship between wage levels and education attainment and work experience. Education and training that improve workers' skills can be treated as investments in human capital.

Data on educational attainment and (estimated) work experience have been used as proxies for skill in this analysis, although not in isolation. It is not suggested that the variables are comprehensive in measuring changes in human capital, as there are a number of competencies involved in jobs that will be the result of innate ability, rather than any training.

\section{Data sources}

After a feasibility study was undertaken, it was decided that the Household Labour Force Survey (HLFS), linked with its annual supplement the New Zealand Income Survey (NZIS), which is run every June quarter, would be the most appropriate data source to adjust a labour series for labour composition. ${ }^{4}$ The HLFS includes almost all the required variables for the analysis, including educational attainment. Experience is based on a person's age and estimated time out of the workforce in education. The key variable that the HLFS lacks is information on hourly wages, which is what the NZIS was linked for. The NZIS commenced in June 1997, with the resulting series beginning in the year ended March 1998.

Once workers have been partitioned into groups, based on the variables of interest, the groups are then weighted according to their relative share of total wages across the measured sector. Two approaches were used to estimate wage shares: the Jorgenson method (or the 'average wage model') that was developed by Jorgenson, Gollog and Fraumeni in 1987, and the BLS method (or the 'wage model') which was developed by the U.S. Bureau of Labour Statistics in 1993.

The Jorgenson method is the simpler of the two, with weightings being based on simple income shares of all labour. In practice, this was undertaken by estimating average hourly wages for each category of worker from the NZIS and applying these average wages to HLFS counts of total hours for each group.

The BLS method is somewhat more complicated, involving regression analysis to estimate hourly wages for each worker, based on the variables of interest. Again, this is based on NZIS data on wages. These hourly wages are then combined with each worker's usual weekly hours worked, obtained from the HLFS, and income shares are then calculated as for the Jorgenson method. In the final analysis, the BLS was used, due to it providing more analytical insight, the ability to control for factors using dummy variables, and better utilisation of data available.

The final regression specification used for the BLS approach is as follows:

$\ln (W)=\beta_{0}+\beta_{1} E X+\beta_{2} E X^{2}+\beta_{3} E D_{1}+\beta_{4} E D_{2}+\beta_{5} E D_{3}+\beta_{6} E D_{4}+\beta_{7} F+\beta_{8} U$ where:

$\begin{array}{lll}W & = & \text { Hourly wage } \\ E X & = & \text { Years of (estimated) experience } \\ E D_{1} & = & \text { School qualification as the highest } \\ E D_{2} & = & \text { Degree as the highest education attained } \\ E D_{3} & = & \begin{array}{l}\text { Post-school training as the highest } \\ \text { education attained (but no school } \\ \text { qualification }\end{array} \\ E D_{4} & =\begin{array}{l}\text { Post-school training as the highest } \\ \text { education attained with school }\end{array} \\ F & \text { qualification } \\ U & =\quad \text { Full-time worker }\end{array}$


Regressions for each year are run separately for males and females because the relative payoffs for education and experience vary between sexes..$^{5}$ Ideally, separate regressions for other breakdowns (eg by industry) would also be conducted, as the payoff for a variable such as education will differ between industries. This was not feasible, due to the limited number of observations in the data. The regressions excluded working proprietor data, due to data limitations. ${ }^{6}$

Aside from the experience variables, all other right-side variables are dummy variables. The variables $F$ and $U$ were treated somewhat differently to the education dummy variables, as their impact, estimated via their regression coefficient, was spread across workers. This is because the variables have a clear impact on wages, but not necessarily on skill, which is what the model is set up to ideally estimate.

Experience was estimated by taking a worker's age, and subtracting five plus their estimated years in education. A series was also estimated using age as the proxy for experience, providing similar results.

Once income shares are calculated for each group, an index is calculated using the Tornqvist formula, which utilises two period income shares of each category of worker, along with its respective movement in labour counts, in calculating movements in compositionadjusted labour.

The key output from the analysis comes from comparing a series of HLFS total hours worked to an identical series, with composition adjustment applied to it through the Tornqvist index. The ratio of the compositionadjusted series to the raw hours series is referred to as a labour composition index, which indicates how the aggregate skill level has increased/decreased over a period.

\section{Results}

From the analysis, the resulting labour composition index from 1998 to 2007 , with a base year of 1998 , is as follows:

\section{Figure 1}

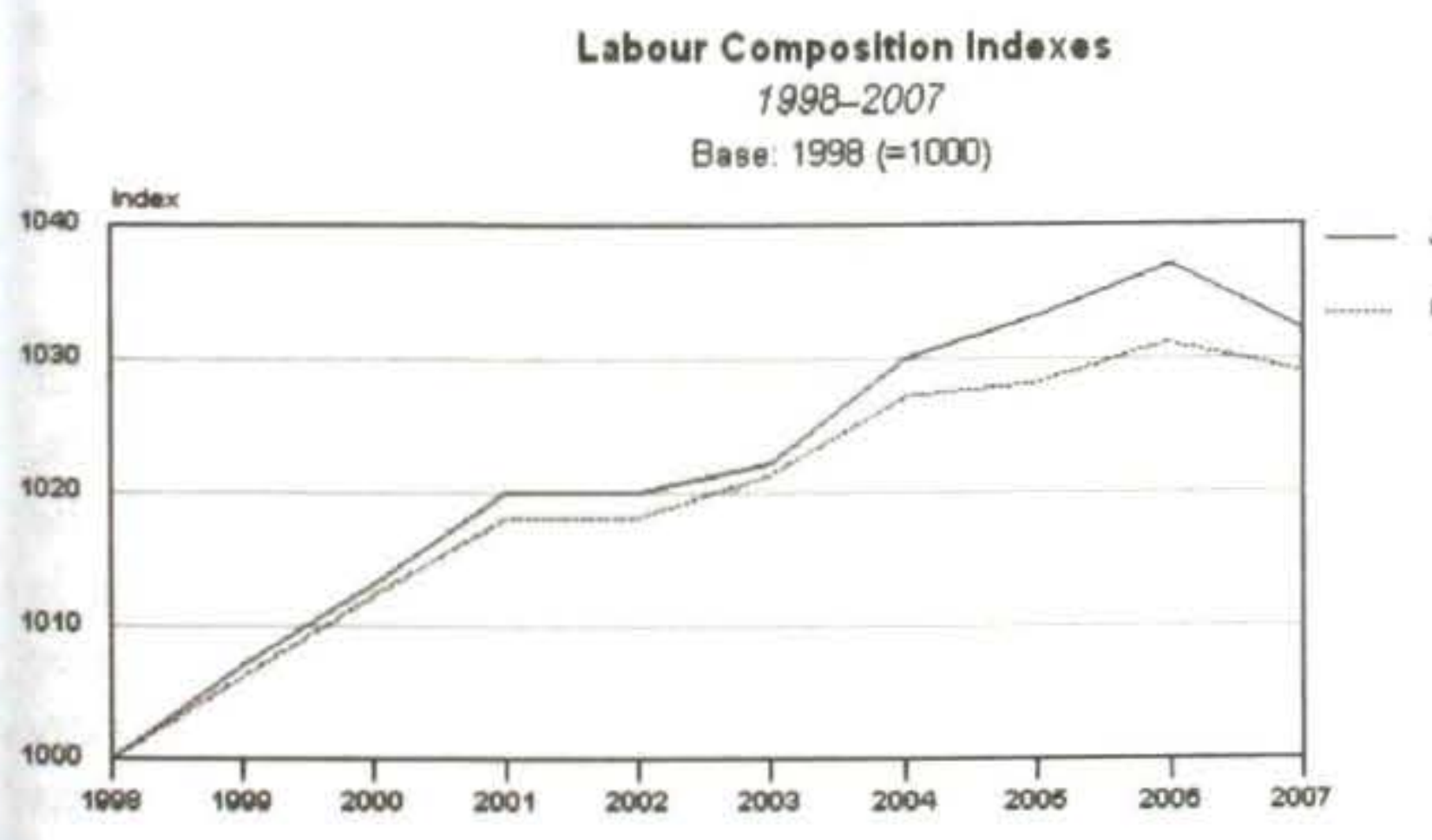

As the series shows, the skill level of labour has increased over the entire series, aside from 2007. The greatest period of growth in skill was between 1999 and 2001. The index compiled using the Jorgenson approach shows slightly stronger growth in skill over the period, although the overall trend of the series is similar. As noted, the BLS approach was the preferred of the two for the final series.

The ultimate application of the labour composition series is to adjust the currently published Statistics NZ productivity series for labour composition, which feeds into a growth accounting framework for decomposing movements in GDP. Figure 2 presents a labour productivity series, calculated as GDP divided by an index of the currently published labour volume series (hours worked across the measured sector, drawn from a variety of datasets). ${ }^{7}$ The composition-adjusted series present the same labour volume series adjusted, using movements in the above labour composition index. Unsurprisingly, the productivity series' growth is dampened for all years aside from 2007.

\section{Figure 2}

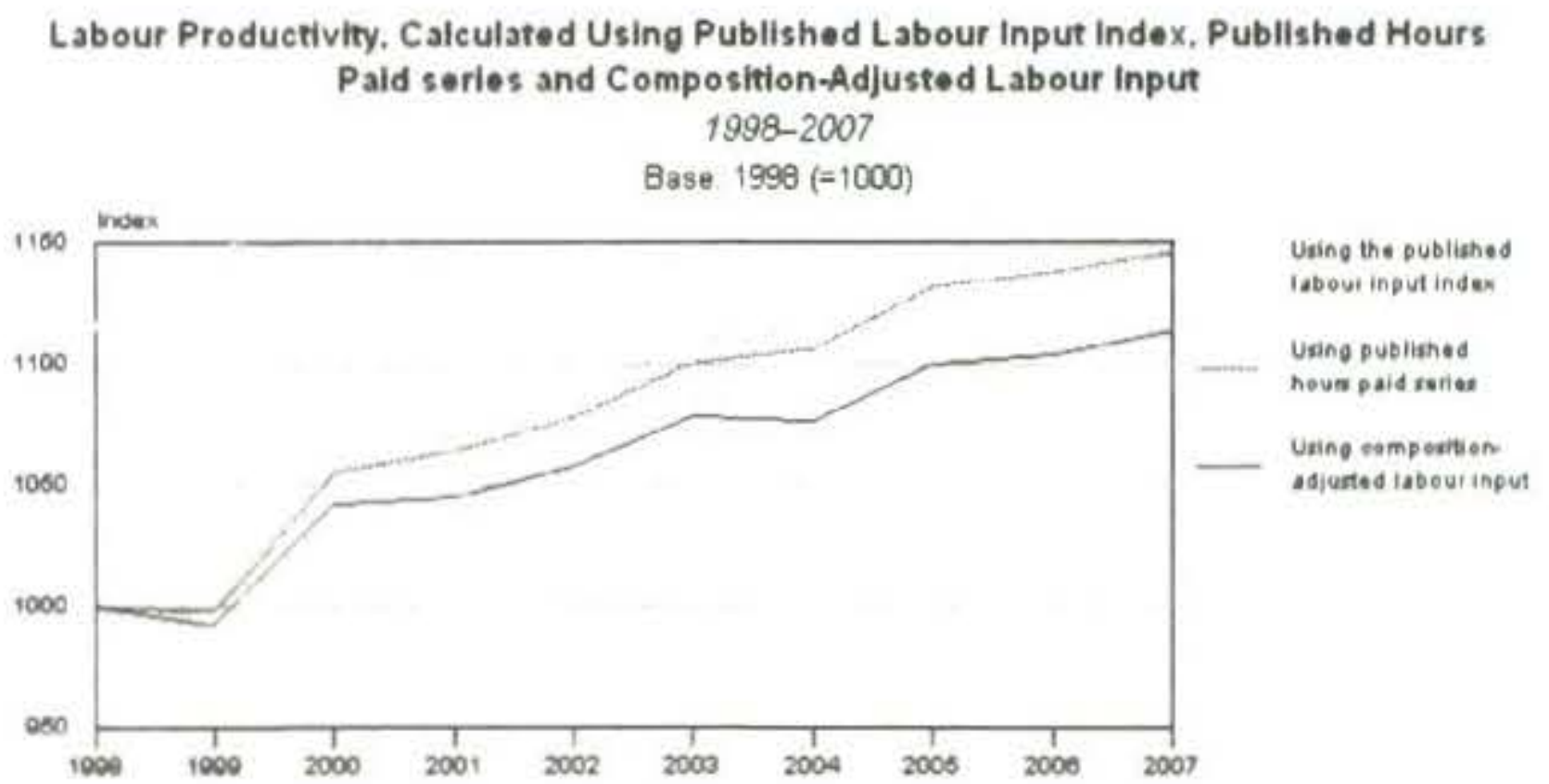

The adjustment can be further extended to a growth accounting framework, in which composition-adjusted labour productivity can be decomposed according to contributions of capital deepening and MFP. This is distinct for the currently published labour productivity series, because increases in skill, which would otherwise be incorporated residually as part as MFP, can now be isolated as a separate component.

\section{Figure 3}

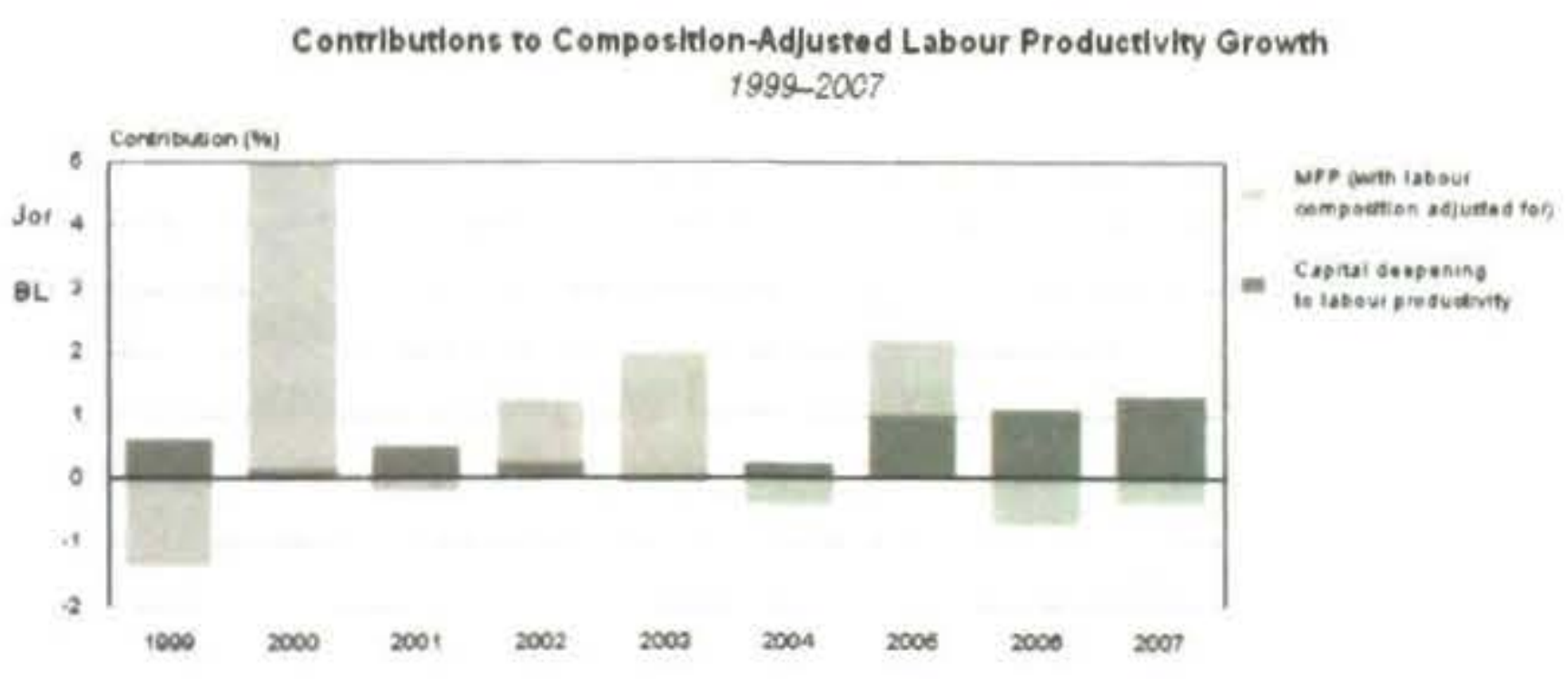

As Figure 3 shows, composition-adjusted MFP has been a significant driver to labour productivity with its relative 
contribution to capital deepening falling over the period. This is much the same story as the current productivity series shows, indicating that labour composition does not radically change the current understanding of New Zealand's productivity performance.

\section{Decomposing the results}

The results above provide some interesting context behind the currently published labour series. The relatively stagnant nature of the labour quality series since 2004 , compared with the strong growth in previous years, provides some support for the 'marginal employee' theory that, in a tight labour market, skill shortages result in less-skilled workers entering the workforce.

Over the years 1998 to 2007, the distribution of experience levels changed significantly. The proportion of workers with over 35 years of estimated experience rose from 14 percent to 19 percent of the measured sector. The proportions of workers with fewer than 5 years experience and with 36 to 40 years, also rose, although to a lesser degree. The proportions for all other groups (ie people with 6 to 35 years of estimated experience) fell between 1998 and 2007. The fact that the groups that have fallen in their proportion of total labour are generally of higher paid areas has put downward pressure on the labour composition index in recent years.

In contrast, the proportion of hours worked by workers with a degree has increased considerably over the same period. rising from 10 percent in 1998 to 15 percent in 2007. This, combined with the proportion contributed by the workers with no recorded qualification falling slightly (from 22 percent to 21 percent), indicates that there has been an upward shift in workers' education levels over the period.

\section{Conclusions}

This paper has sought to provide some context behind, and results of, applying a composition-adjustment to Statistics NZ's productivity series. As the paper has argued, there are significant conceptual benefits for this approach and although there are complications with its application, such as the use of proxy for skill, the resulting composition-adjusted productivity series adds a new layer to the analysis of New Zealand's recent productivity performance.

As noted, all composition-adjusted series released are considered as experimental, and are partly released with the intention of receiving feedback from users on the series.

More details on the series can be found in the recently released information paper Accounting for changes in labour composition in the measurement in labour productivity, available on the Statistics NZ website (www.stats.govt.nz).

\section{Notes}

1. In 2004 (the latest year for which current price industry value added data are available), the measured sector covered approximately 73 percent of the economy. It excludes the following industries: government administration and defence, health, education, ownership of owneroccupied dwellings and property services.

2. Under certain assumptions, including that of complete coverage of inputs, a productivity estimate can ideally be considered as a measure of 'disembodied technological change'. Disembodied technological change leads to a shift in the overall level of production through generalised improvements in knowledge, methods and processes, as well as the enhancement of facilitating factors such as information and transport networks.

3. Although the basis of this paper is derived from human capital theory, it is recognised that the concept of human is much wider than that discussed in this paper. For example, the social implications of changes in a country's human capital are not considered in this paper.

4. A feasibility study into developing a compositionadjusted labour volume series was undertaken and presented at the 2006 Labour, Employment and Work conference by McNaughton (2006). This includes more detailed information on the pros and cons of each of the labour series available in New Zealand when applied in this context.

5. Pooled regressions were considered as the coefficients are very stable over time, but made little difference to the series.

6. When weighting labour using wages, the incorporation of working proprietors becomes problematic because the wage component of working proprietors' income is hard to ascertain. Because of this, the regression approach was undertaken using only employees, and the coefficients values were applied to working proprietors, based on their category of skill.

7. The currently published Statistics NZ labour volume series is based on a number of datasets, due to differences in coverage/strengths of the datasets available. For recent years, the series is compiled based on Linked Employer-Employee Data (LEED), the Quarterly Employment Survey (QES), the HLFS and the census. This series was not directly quality-adjusted, but rather adjusted 
using HLFS/NZIS information, because the variables of interest for this exercise are not available in most of the datasets that compile the labour volume series.

\section{References}

Bureau of Labor Statistics (1993). "Labor Composition and U.S. Productivity Growth, 1948-90", U.S. Department of Labor, Bureau of Labor Statistics, Bulletin 2426, Washington DC, U.S. Government Printing Office.

Holmwood, R., Lau, E., Richardson, C. and Wallis, G. (2006). "Experimental composition adjusted labour input measure - an update", Economic Trends, 631, June 2006.

Hyslop, D. and Maré, D. (2008). "Cyclical Earnings Variation and the Composition of Employment", Statistics New Zealand. http://www.stats.govt.nz/leed/reports/cyclicalearnings-variation-and-the-composition-ofemployment.htm

Keeley, B. (2007) "Human capital: How what you know shapes your life", OECD Insights. OECD

Mason, G. and Osborne, M. (2007). "Productivity, Capital-Intensity and Labour Quality at Sector Level in New Zealand and the UK", Treasury Working Paper 07/01, New Zealand Treasury. http://www.treasury.govt.nz/workingpapers/2007/ twp07-01.pdf

Jorgenson, D., Gallop, F. and Fraumeni, B. (1987). Productivity and U.S. economic growth, Cambridge MA, Harvard University Press.

McNaughton, T. (2007). "Quality-adjusted labour productivity measures", in Labour Market Statistics: 2006, Wellington, Statistics NZ. www.stats.govt.nz/analytical-reports/labourmarket-statistics-06.htm

Organisation for Economic Co-operation and Development (2001). OECD Manual: Measuring Productivity; Measurement of Aggregate and Industry-Level Productivity Growth, OECD, France.

Reilly, R., Milne, W. and Zhao, S. (2005). "Qualityadjusted Labour Inputs", Australian Bureau of Statistics Research Paper No 1351.0.55.010, Canberra, ABS.

Statistics Canada (2003). "A Revision of Statistics Canada's Estimates of Labour Input for the Productivity Accounts", Statistics Canada.
Statistics New Zealand (2008) "Accounting for changes in labour composition in the measurement of labour productivity", Wellington, Statistics NZ. www.stats.govt.nz/productsandservices/inforeleas es/productivity-statistics.htm

Statistics New Zealand (2006) "Productivity Statistics: Sources and Methods", Wellington, Statistics NZ. www.stats.govt.nz/productsandservices/inforeleas es/productivity-statistics.htm

Szeto, K. and McLoughlin, S. (2008) "Does Quality Matter in Labour Input? The Changing Pattern of Labour Composition in New Zealand". Treasury working paper 08/01, New Zealand Treasury. www.treasury.govt.nz/publications/researchpolicy/wp/2008/08-01//twp08-01.pdf

Zheng, S. (2005). "Estimating Industry-Level Multifactor Productivity for the Market-Sector Industries in Australia: Methods and Experimental Results", Australian Bureau of Statistics Research Paper No 1351.0.55.004, Canberra, ABS.

Zoghi, C. (2007) "Measuring Labor Composition: A Comparison of Alternate Methodologies", U.S. Bureau of Labor Statistics. http://www.bls.gov/bls/fesacp1 121407.pdf

\section{Author}

Thomas McNaughton

Statistical Analyst

Macro-Economic Statistics Development Unit

Statistics New Zealand

P.O. Box 2922

Wellington

Thomas.McNaughton@stats.govt.nz 